FEATURE

Debra Leaker

\section{Office for National Statistics}

\section{SUMMARY}

The gender pay gap is a measure of the difference between the earnings of men and women. This article presents estimates of the gender pay gap from the Annual Survey of Hours and Earnings, the Labour Force Survey and the New Earnings Survey panel data set. It examines how different personal and labour market characteristics influence the earnings of men and women.

The results show that the gender pay gap of full-time employees has narrowed since the introduction of the Equal Pay Act in 1975. However, the gender pay gap varies depending on an individual's circumstances. For example, the number of dependent children, company size and type of occupation are major factors in the difference between men and women's earnings.

\title{
The gender pay gap in the UK
}

T he Equal Pay Act 1970 came into force in 1975 . The act sets legislation with the aim of eliminating discrimination in pay and other terms and conditions between men and women working in similar jobs. According to data published by the Equal Opportunities Commission ${ }^{1}$ (now part of the Commission for Equality and Human Rights), 'the average woman working full-time could lose out on $£ 330,000$, in comparison with men's earnings, over the course of her working life'.

The gender pay gap is a measure of the difference between the earnings of men and women. It is determined by calculating women's average pay as a percentage of men's. The pay gap is the difference between this and 100 per cent. So, for example, the gender pay gap is 15 per cent if women's pay is 85 per cent of men's pay.

The gender pay gap has been widely researched. Research published by the Women and Equality Unit ${ }^{2}$ concludes that the main factors influencing the gender pay gap are:

- human capital differences - differences in educational levels and work experience

- part-time working - the pay difference between full-time and part-time is large. As part-time working is concentrated among women, this is a major contributor to the gender pay gap

- travel patterns - on average, women spend less time commuting than men
- occupational segregation - women's employment is highly concentrated by occupation, with female-dominated occupations often being the lowest paid

- workplace segregation - high concentrations of female employees are associated with relatively low rates of pay

Other research has found that part of the gender pay gap is the result of rational choices made by the different sexes and not all due to discrimination.

The UK has two main sources of earnings data:

- the Annual Survey of Hours and Earnings (ASHE), formerly known as the New Earnings Survey (NES), and

- the Labour Force Survey (LFS)

This article presents the gender pay gap in both ASHE and the LFS. Initially, a brief description of both data sources is given, followed by a comparison of the two sources using age, occupation and region. The subsequent section contains more detailed investigations using ASHE and the LFS. Finally, the NES panel data set, a single longitudinal data set dating back to 1975 , is used to identify long-term trends in the data.

\section{Annual Survey of Hours and Earnings}

In 2004, ASHE replaced the NES. ASHE provides information on the levels, 
distribution and make-up of earnings and hours for employees within industries, occupations and regions in Great Britain. It is based on a 0.8 per cent $(1.0$ per cent prior to 2007) sample of employee jobs taken from HM Revenue \& Customs pay-as-youearn (PAYE) records. Employers are asked to provide detailed information on the earnings and hours of their employees, and the characteristics of the workplace. Since the information is provided by businesses, the data collected generally come direct from the payroll systems. ASHE does not cover employees who work for businesses whose turnover is lower than the VAT threshold and/or whose employees earn less than the PAYE threshold. The 2007 ASHE is based on approximately 142,000 returns. The Department of Enterprise, Trade and Investment conducts a similar but separate survey for employees in Northern Ireland, to allow for UK estimates to be calculated.

ASHE includes improvements to the coverage of employees not originally in the NES sample, imputation for item nonresponse, and the weighting of earnings estimates to overcome unit non-response. The questionnaire for ASHE was improved in 2005, including improvements to the collection of data relating to allowances and incentive pay. NES data for 2003 and earlier were reworked using the ASHE imputation and weighting methodology; however, the data do not take account of the improved coverage which has resulted in a discontinuity in the series.

In 2007, another discontinuity occurred due to further methodological improvements that were made. These included changes to the sample design itself, as well as the introduction of an automatic occupation coding tool, ACTR.

\section{Labour Force Survey}

The LFS is a quarterly sample survey of about 52,000 households living at private addresses in the UK, representing about 0.2 per cent of the population. The survey asks respondents for information on their personal circumstances and labour market status. Information is collected about their hours and earnings in their main and second job (if they have one). The LFS covers groups such as temporary employees, part-timers and the low paid, who are not necessarily covered by employers' records. The LFS has moved from reporting on a seasonal to a calendar quarter basis. Calendar quarter data sets are currently available for 1997, 1999, and 2001 to 2007 only. In order to present a complete time series, the equivalent seasonal quarter has been shown for 1998 and 2000.

\section{ASHE v LFS}

Both ASHE and the LFS collect information on hours and earnings. However, due to different data collection methods, the accuracy of the information collected varies. For ASHE, the information is almost always completed from employers' pay records and so is a good source for providing estimates on the level of earnings. In comparison, for the LFS, the information is collected from each member of the household. Where members of the household are not present, the information about the person is provided by another member of the household, usually a related adult. This is known as proxy response. The percentage of missing data for income is higher than for most other variables due to proxy inability or unwillingness to answer.

Previously it was thought that the LFS data were an unreliable source for earnings analysis. Ormerod and Ritchie

Figure 1

\section{Gender pay gap of full-time employees of working age}

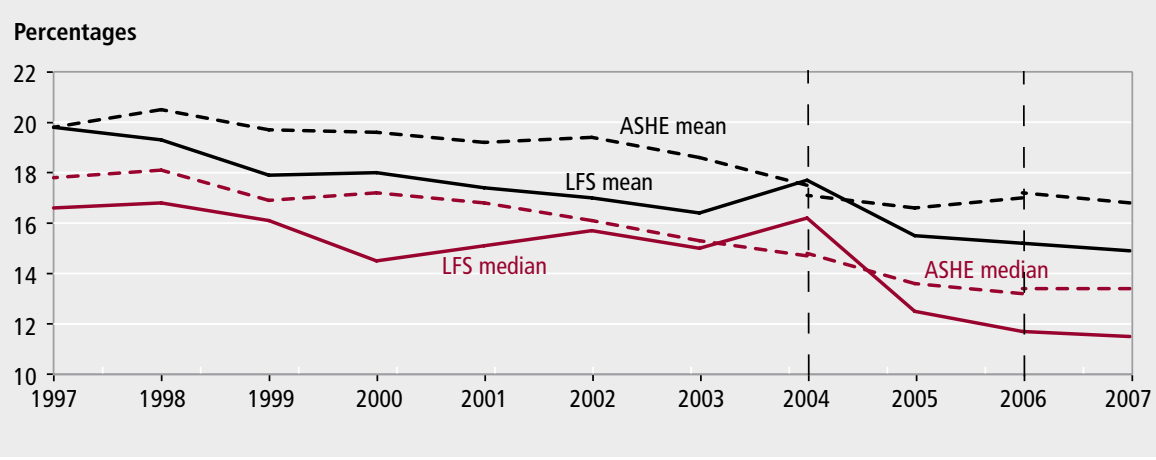

\section{Note:}

Vertical lines represent discontinuities in 2004 and 2006 ASHE results.

Source: Annual Survey of Hours and Earnings, Labour Force Survey

(2007) showed that the two sources are more consistent than first thought and concluded that earnings data in the LFS are an unbiased predictor for earnings in ASHE for the majority of the pay distribution. It reported that there were some differences at the higher end of the pay distribution, but the resource and complication to link both surveys outweighed the benefits in linking. The project supported the use of LFS data for earnings analysis for personal characteristics not available in ASHE.

\section{Measuring the gender pay gap}

The median is the most common measure used to summarise average earnings. This is the middle point of the population, with exactly the same number of people earning below this amount as above. In some instances, it can be more suitable to present the median rather than the mean, as the latter can be influenced by the relatively few extreme values in a pay distribution.

Although the gender pay gap provides a useful comparison between the earnings of men and women, it does not necessarily indicate differences in rates of pay for comparable jobs, such as the proportions in different occupations and their length of time in jobs.

Various methods can be used to measure the earnings of women relative to men. The preferred method is to use hourly earnings excluding overtime for full-time employees. Including overtime can skew the results because men work relatively more overtime than women. Including part-time employees could have a similar effect because women make up a much bigger proportion of part-time employees than men and there is a large difference in hourly rates between full-time and parttime employees. Additionally, using weekly earnings would not take into account that women generally work fewer hours in the working week than men.

\section{Comparing the gender pay gap in ASHE and the LFS}

To make comparisons between the two data sources, the gender pay gap has been calculated on pay and hours including overtime, as this cannot be removed in the LFS data, for working age employees (men aged 16 to 64 and women aged 16 to 59). The gender pay gap is based on the hourly wage of men and women working full-time, which is defined as working more than 30 paid hours a week, 25 or more paid hours in the teaching profession.

Figure 1 shows that the median and mean gender pay gap of full-time employees 
Figure 2

Median gender pay gap of full-time working-age employees:
by age band, 2007

Percentages

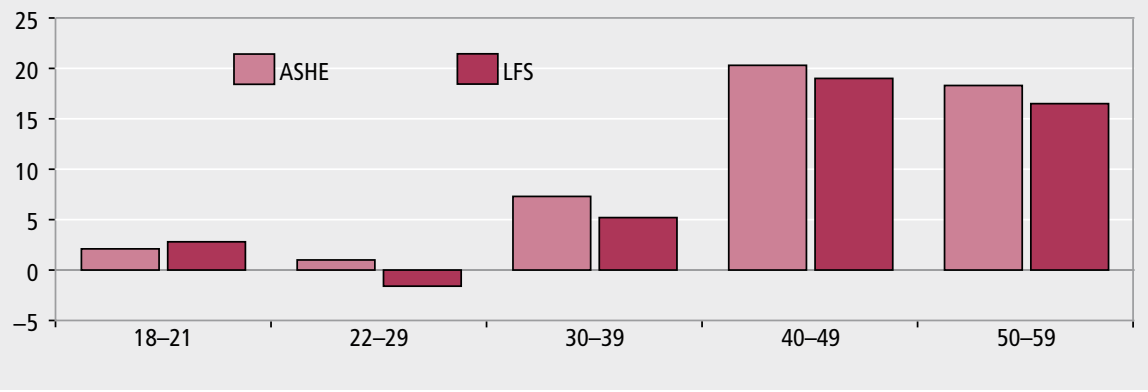

Source: Annual Survey of Hours and Earnings, Labour Force Survey

\section{Figure 3}

\section{Full-time hourly earnings excluding overtime: percentiles and} mean, 2007

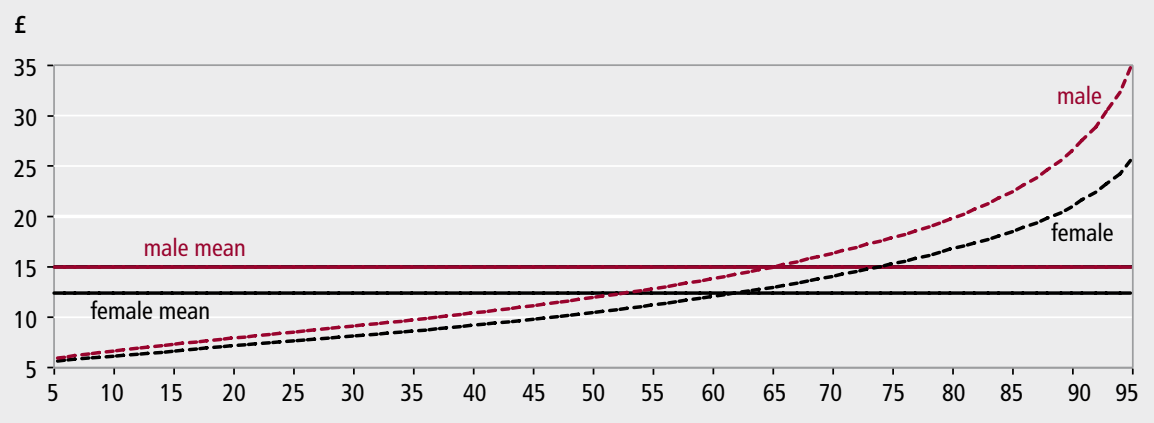

Source: Annual Survey of Hours and Earnings

of working age in both ASHE and the LFS has closed considerably since 1997 . The mean estimates are consistently higher than the median estimates, which suggest that there are more men at the higher end of the pay distribution.

Unless otherwise stated, the remainder of this article will focus on the median measurement of the gender pay gap, using hourly earnings.

\section{Age}

Figure 2 represents the gender pay gap of full-time employees by age band. Both data sources show that earnings are similar when entering the job market, at 18 to 21 years old, but a gender pay gap appears after approximately ten years, for those aged from 30 to 39 . The gender pay gap increases for the 40 to 49 age group. Older women are more likely to have career breaks from paid work to care for children and other dependants. These breaks impact on women's level of work experience, which in turn can impact on their pay rates.

Figure 2 shows that the largest pay gap of full-time employees in 2007 exists for those aged 40 to 49 , at 20.3 per cent in ASHE and 19.0 per cent in the LFS. They are closely followed by those aged 50 to 59 , where the pay gap is 18.3 per cent and 16.5 per cent, respectively.

\section{Occupation}

Occupations are coded according to the 2000 Standard Occupational Classification, where nine major occupations are used.

In both ASHE and the LFS, full-time women earn less than full-time men in every occupation; the widest gender pay gap is visible in the male dominated skilled trades major group (such as painters and decorators), at 26.4 per cent in ASHE and 24.5 per cent in the LFS. A greater proportion of women than men work in low-paid occupations and women tend to be under-represented in the higher-paid jobs within occupations. More detailed analysis by occupation using ASHE is presented later in this article.

\section{Region}

On average, full-time women are paid less than full-time men in all regions in both ASHE and the LFS. In ASHE, the largest pay gap was in the South West government office region, at 16.8 per cent (14.3 per cent in the LFS). In the LFS, the largest difference was in the South East region, where women's median pay was 18.5 per cent less than their male counterparts (16.2 per cent in ASHE).

The gender pay gap of full-time employees for both ASHE and the LFS by age, region and occupation generally show the same patterns. However, results for those working part-time are less comparable and less reliable. The inconsistencies could be due to several reasons:

- smaller sample sizes in the LFS

- self definition of full-time and parttime in the LFS

- rounding errors from respondents/ proxy response in the LFS

For the remainder of this article, only ASHE will be used for analysis on the part-time gender pay gap.

\section{ASHE results}

The ASHE results are calculated from hourly earnings excluding overtime for all employees (not restricted to working age). This section of the article focuses on information provided from employer records and looks at characteristics such as company size, distribution of hours and occupation. More information on the earnings of men and women by sector, industry and travel to work areas is available in the ASHE survey results at www.statistics.gov.uk/statbase/ product.asp?vlnk $=13101$

Unless otherwise stated, the results shown below are from the 2007 ASHE data set.

According to results in the 2007 ASHE, median hourly earnings excluding overtime were $£ 11.34$, up 2.8 per cent from $£ 11.03$ in 2006 for full-time employees on adult rates whose earnings were not affected by absence.

In 2007, the median hourly earnings of full-time men increased by 2.8 per cent compared with 3.1 per cent for women. The stronger growth in women's hourly earnings has resulted in a reduction of the gender pay gap by 0.2 percentage points to 12.6 per cent.

Figure 3 shows the distribution of earnings for men and women. The tenth percentile means that 90 per cent of employees earn more than this level of pay, while 10 per cent earn less. It shows the impact high earners have on the mean compared with the median. It also shows a widening of the pay gap of full-time employees by earnings when moving along the pay distribution: the gender pay gap at the tenth percentile is 7.7 per cent, 
compared with 20.9 per cent at the 90th percentile.

\section{Distribution of hours}

The gender pay gap is usually presented separately for full- and part-time employees. Full-time is defined as those contracted to work more than 30 hours a week, or 25 hours or more in the teaching profession. Over recent years, flexible working has become more popular, meaning there is less of a distinction between full- and part-time workers.

In 2007, just over 70 per cent of all employees worked between 30 and 50 basic hours per week. The pay gap is widest for those working between 30 and 40 hours per week, at 19.0 per cent, closely followed by those working 50 hours or more per week, at 18.2 per cent. Figure 4 shows that men earn more than women across the hours distribution, except for those working between ten to 20 and 20 to 30 hours per week, where women's earnings are slightly higher than men's.

\section{Company size}

The gender pay gap of full-time employees does not appear to vary considerably by the number of people employed in the whole enterprise (all units in a particular business are attached to an enterprise). The pay gap ranges from 12.4 per cent for companies with less than 25 employees to 18.4 per cent for those employing between 25 and 49 .

The results show that the gender pay gap for part-time employees varies substantially. Part-time women are more likely to work in smaller companies (less than 25 employees) where the pay gap is 11.3 per cent. In comparison, part-time women earn more than part-time men in larger firms (500 or more employees), where the hourly pay is $£ 7.39$ for women and $£ 7.05$ for men, resulting in a gender pay gap of -4.8 per cent (a negative pay gap indicates that women earn more than men).

\section{Occupation}

Analysis by major occupational groups shows that the widest pay gaps among full-time employees are for skilled trades occupations (25.4 per cent), managers and senior officials (23.0 per cent), and process, plant and machine operatives (21.7 per cent). The narrowest pay gaps are for professional occupations (3.8 per cent) and sales and customer service occupations (5.9 per cent).

As with full-time employees, the widest pay gap for part-time employees is in the skilled trades occupations, at 30.5 per cent. The highest hourly pay among part-time employees is in the professional occupations, such as chemists and teachers, where the median pay for men and women is $£ 20.63$ and $£ 19.78$ respectively, resulting in a gender pay gap of 4.3 per cent. In contrast, the occupations with the lowest pay are the elementary occupations, such as traffic wardens and bar staff, where the pay for men is $£ 5.86$ and for women $£ 5.82$, resulting in a pay gap of 0.7 per cent.

Results by major occupational groups hide variation in the pay differences of men and women. Analysis by minor occupational groups shows that men generally earn more than women across occupations. However, there are a few exceptions: full-time women, for example, earn more than full-time men in secretarial and related occupations, with median hourly earnings of $£ 9.35$ compared with $£ 8$.84, resulting in a gender pay gap of -5.8 per cent. For part-timers, in the health and social welfare associate professionals, women's average hourly earnings are $£ 13.54$, while men's are $£ 11.05$, resulting in a gender pay gap of -22.5 per cent.

Further investigations by age within occupation show a significant change in the employment patterns of women. While the number of full-time women in employment declines, the equivalent part-time numbers increase significantly. This changing status

\section{Figure 4}

\section{Median hourly earnings excluding overtime: by hours worked, 2007}

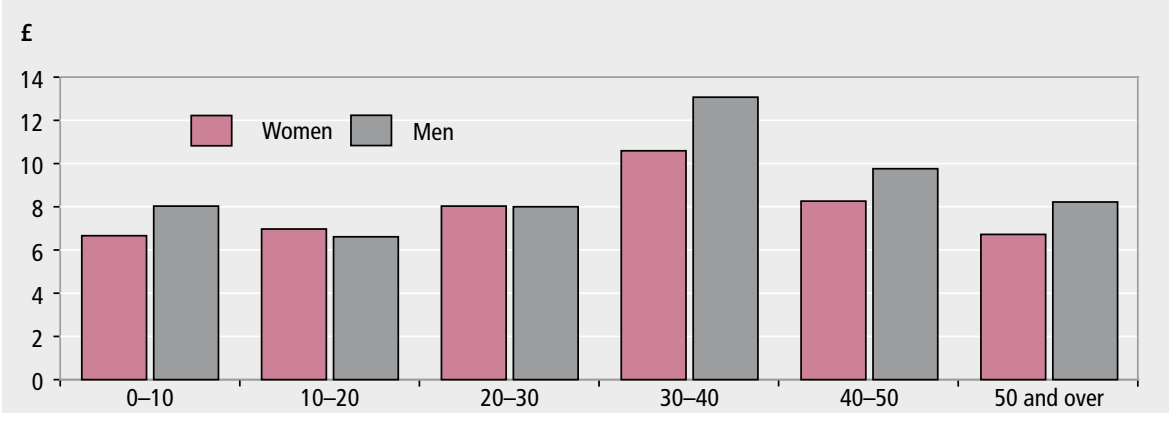

Source: Annual Survey of Hours and Earnings

in women's employment occurs at early- to mid-thirties, which could possibly be due to women altering their working patterns to fit around family commitments.

\section{LFS results}

According to the LFS, women represented 48 per cent of the working-age labour force in April to June 2007. In the same period, the employment rate for women of working age was 70 per cent, compared with 78 per cent for men.

In April to June 2007, some 41 per cent of women of working age in employment were in part-time employment, compared with only 10 per cent of men.

The LFS results shown in Table $\mathbf{1}$ are calculated from actual pay and hours including overtime for an individual's main job, restricted to those of working age. Pay excluding overtime is not available in the LFS, as overtime payments are not asked for separately. The survey does not collect information on earnings from the selfemployed. In the LFS, whether a respondent is working full-time is down to their own assessment of their job; it is not determined by the number of hours worked.

This section of the article focuses on a range of personal or family characteristics, such as qualifications, ethnicity and family status. Unless otherwise stated, the results shown below are from the April to June 2007 LFS data set. The LFS estimates at this detailed level are consistent with the UK population estimates published in 2003, whereas those in the recent Labour Market Statistics First Release are based on more up-to-date population figures.

\section{Family characteristics}

The gender pay gap of full-time employees varies by married/cohabiting status.

Men and women who are not married or cohabiting have similar hourly pay, $£ 8.72$ for men and $£ 8.82$ for women, resulting in a gender pay gap of -1.1 per cent. However, the gender pay gap for married/cohabiting couples is 14.5 per cent.

The gender pay gap increases with the number of children present in a family. The average hourly pay of a full-time woman with one dependent child is $£ 9.32$, compared with $£ 10.63$ for full-time men, resulting in a gender pay gap of 12.3 per cent. In comparison, in a family where four or more dependent children are present, the gender pay gap stands at 35.5 per cent.

\section{Personal characteristics}

LFS respondents can be defined as having a long-term disability covered by the 
Disability Discrimination Act, or a worklimiting disability, or both. The hourly pay of a full-time disabled woman is $£ 9.07$, compared with $£ 9.70$ for full-time disabled men, resulting in a gender pay gap of 6.5 per cent. In comparison, the results for those who do not classify themselves as disabled show the hourly pay of a full-time woman is $£ 9.61$, compared with $£ 10.92$ for full-time men, resulting in a gender pay gap of 12.0 per cent.

The gender pay gap of full-time employees varies considerably across ethnic groups. The widest pay gaps are for Asian/ Asian Black employees at 12.6 per cent and White employees at 12.4 per cent. Black/ Black British women earn on average $£ 11.43$ per hour while their male counterparts earn $£ 10.74$ per hour, resulting in a gender pay gap of -6.4 per cent.

\section{Educational attainment}

Historical differences in the level of qualifications held by both sexes are said to have contributed to the pay gap. However, the number of men and women holding higher educational qualifications continues to increase. According to the LFS, the level of qualification obtained has a relatively small impact on the gender pay gap. The gender pay gap of full-time employees is narrowest for those whose highest qualification is GCSEs, at 12.7 per cent. The widest pay gaps are for those educated to
Table 1

Median hourly earnings and gender pay gap of full-time working age employees, April to June 2007

Not seasonally adjusted

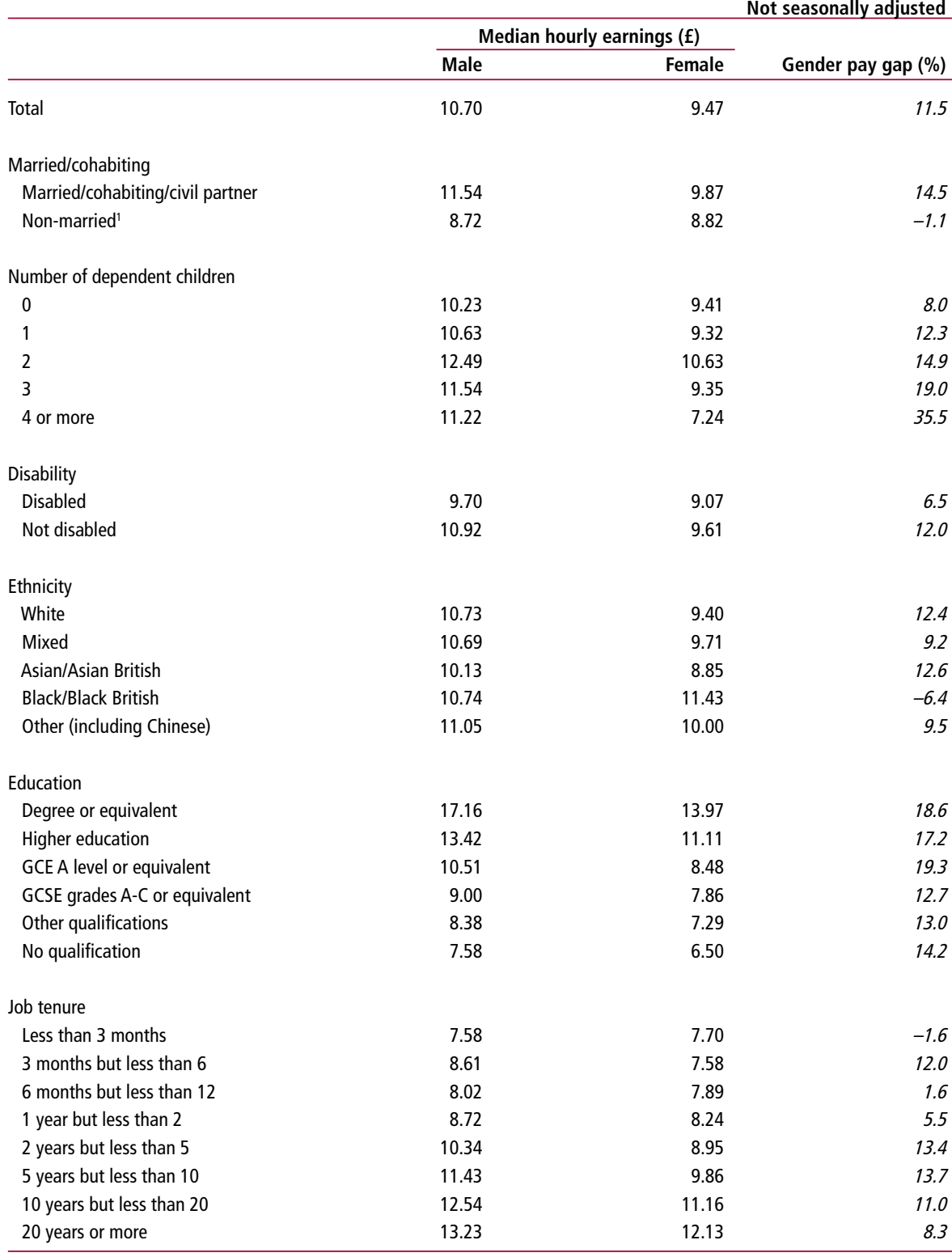

Note:

1 Non-married includes those who are single, widowed, divorced or separated from their spouse.

Source: Labour Force Survey
A level, closely followed by those educated to degree or equivalent level, where the gender pay gap is 19.3 per cent and 18.6 per cent, respectively.

\section{Job tenure}

The LFS asks respondents how long they have continuously worked for their current employer. Information on how long the respondent has been in the workforce excluding career breaks is not available.

In general, the gender pay gap becomes more visible when a full-time employee has been in post for two or more years, where the pay gap is 13.4 per cent. For those who have worked in the same company for 20 years or more, the gap stands at 8.3 per cent.

Over the last decade, the biggest change can be seen in the group that has been continuously employed in the same company for more than six months, but less than a year. In 1997, the gender pay gap for this group was 14.9 per cent compared with 1.6 per cent in 2007 .

\section{New Earnings Survey panel data set \\ The NES panel data set is a single} longitudinal data set containing a subset of the ASHE survey for each year since 1975. It only includes the main job for each person, so individuals are included once and can be tracked over time. It also excludes individuals who are allocated temporary National Insurance numbers, as these are not unique. Only a relatively small number of cases are excluded and the data are not weighted or adjusted for item non-response and so will give slightly different results from the full ASHE survey.

At the time of publication, the latest panel data set available includes data up to and including 2006.

Cross-sectional analysis of the panel data set shows that the gender pay gap of full-time employees has been declining over time, and is now at its narrowest since the Equal Pay Act came into force in 1975 (Figure 5). At that time, the pay gap between men's and women's average hourly earnings in full-time employment was 28.7 per cent compared with 12.0 per cent in 2006.

Figure 6 shows the gender pay gap by individual years of age in 1975 and 2006. The gender pay gap for all ages has declined over the last 30 years. In 1975, the gap appeared on entering the job market at 18 , generally increasing to around the age of 40 before levelling off and slightly falling for those in their late fifties. In 2006, the gender pay gap fluctuates around equality 


\section{Figure 5}

\section{Median gender pay gap of full-time employees of working age}

\section{Percentages}

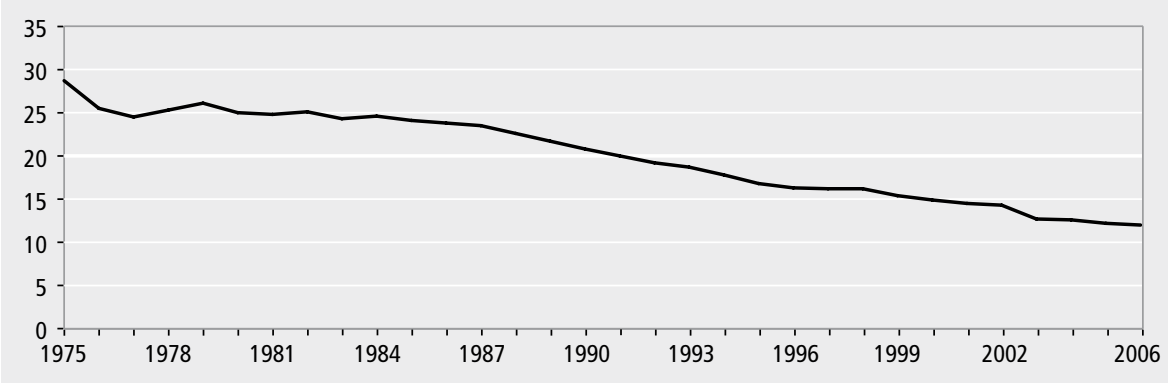

Source: New Earnings Survey panel data set

\section{Figure 6}

Median gender pay gap of full-time employees: by age

\section{Percentages}

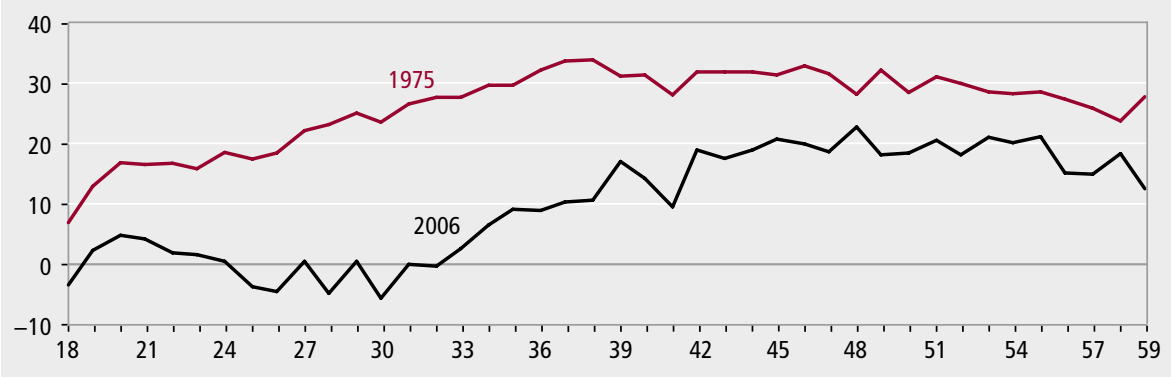

Source: New Earnings Survey panel data set

for individuals up to the age of 34 , then increases before levelling off around 46 years of age and falling again for those in their late fifties. This trend may be a consequence of women having children later in life in 2006 compared with 1975.

\section{Conclusions and future work}

This article has presented analysis of the gender pay gap using ASHE, the LFS and the NES panel data set. It shows that in spite of legislation, a gender pay gap still exists. The results suggest that the position of women working full-time has improved compared with that of full-time men. However, the gender pay gap varies depending on an individual's circumstances. For example, the number of dependent children, company size and type of occupation are major factors in the difference between men's and women's earnings.

Results also show that, in 1975, the gender pay gap was visible when comparing the hourly earnings of men and women from 18 years of age. Some 30 years later, by 2006 , this pay gap was not evident until the age of 34 .

This article focuses on information from ONS surveys and does not look into how much of the gender pay gap is down to personal choice, that is, women choosing to take lower-paid jobs to concentrate on their families.

ONS is carrying out further investigations into the decomposition of the gender pay gap using econometric modelling; these will be published later in 2008 .

\section{Notes}

1 The Gender Agenda, Equal Opportunities Commission, July 2007.

2 The Gender Pay Gap, Women and Equality Unit, July 2001.

\section{CONTACT}

《elmr@ons.gsi.gov.uk

\section{REFERENCES}

Daniels H (2008) 'Patterns of pay: results of the Annual Survey of Hours and Earnings, 1997 to 2007', Economic \& Labour Market Review 2(2), pp 23-31.

Equal Pay Act 1970 at www.opsi.gov.uk/acts/acts1970/pdf/ ukpga_19700041_en.pdf

Ormerod C and Ritchie F (2007) 'Linking ASHE and LFS: can the main earnings sources be reconciled?', Economic \& Labour Market Review 1(3), pp 24-31.

The Kingsmill Review of Women's Pay and Employment, Women and Equality Unit, 2001 